\title{
Development of the Popular and Solidarity Economy in Ecuador 2010 - 2019
}

\author{
Desarrollo de la Economía Popular y Solidaria \\ en el Ecuador 2010 - 2019
}

Joffre Edgar Boza Aguirre

Magister, Universidad Católica de Cuenca, La Troncal, Ecuador, jebozaa@ucacue.edu.ec https://orcid.org/0000-0002-9226-7348

Joffre Campoverde Saldaña

Magister, Universidad Católica de Cuenca, La Troncal, Ecuador, jrcampoverdes@ucacue.edu.ec https://orcid.org/0000-0003-3071-1738

Girabel Nathalia Ávila Manzano

Student, Universidad Católica de Cuenca, La Troncal, Ecuador, avilagirabel@ucacue.edu.ec https://orcid.org/0000-0002-7981-2591

\section{Abstract}

Ecuador has considered the Popular and Solidarity Economy (EPS) as one of the best techniques to satisfy the economic needs that arise in society, because this new form of organization allows to undertake and improve the enterprises that have arisen, improving the economic level of those who undertake. Therefore, several articles related to the research topic have been reviewed in order to observe the development that this economy has had in the last ten years in Ecuador. For this reason, this work is descriptive in that it makes a critical review of literature and applies a qualitative methodology, since it describes the extent to which the economy has improved in Ecuador and emphasizes the savings and credit cooperatives, which have had a successful economic development in the last decade, since they have increased 
both their economic capital and their members, and there are currently 887 cooperatives. These cooperatives have been substantially important when it comes to approving loans for small and medium entrepreneurs, because their interest rate is low and with payment facilities, which has allowed the increase of enterprises in different sectors, especially in rural areas.

\section{Resumen}

Ecuador ha considerado a la Economía Popular y Solidaria (EPS) como una de las mejores técnicas para satisfacer la necesidad económica que se presenta en la sociedad, debido que esta nueva forma de organización permite emprender y mejorar los emprendimientos que han surgido mejorando el nivel económico de quienes emprenden. Por ello se ha revisado varios artículos relacionado a la temática de 80 investigación para poder observar el desarrollo que ha tenido esta economía en los último diez años en el Ecuador. Por tal razón este trabajo es de tipo descriptivo ya que hace una revisión crítica de literatura y aplica una metodología cualitativa, pues se describe en qué medida ha mejorado la economía en el Ecuador y se hace énfasis a las cooperativas de ahorro y crédito quienes han tenido un exitoso desarrollo económico en la última década, ya que han aumentado tanto su capital económico, como sus socios, y actualmente hay 887 cooperativas. Estas cooperativas han sido sustancialmente importantes a la hora de aprobar créditos para los pequeños y medianos emprendedores, porque su tasa de interés es baja y con facilidades de pago, lo que ha permitido el aumento de emprendimientos en diferentes sectores especialmente en los rurales.

\section{Palabras clave/ Keywords}

Popular and solidarity economy, entrepreneurship, entrepreneurs, savings and credit cooperatives.

Economía popular y solidaria, emprendimiento, emprendedores, cooperativas de ahorro y crédito.

\section{Introduction}

"The solidarity economy movement in Latin America has been included in the arguments of communitarianism. As what happened with respect to Anglo-Saxon communitarianism, the solidarity 
economy is formed with identity opposed to individualism and liberal perspectives on economic matters" (León, 2019, p25).

Ecuador has considered the Popular and Solidarity Economy (EPS) as one of the best techniques to satisfy the economic needs of society, since it has been considered an alternative economic model in the country, because this new form of organization has allowed the country's inhabitants to undertake and thus help themselves economically and help society by creating new sources of work for the population.

Orellana-OrellanaOet al., considers "The popular and solidarity economy as an entity open to all public, in charge of economic and social inclusion, with national jurisdiction, endowed with legal personality "(2018, p. 84).

81 While it is known that savings and credit cooperatives are one of the outlets that businesses use to develop, this is due to the ease of payment and the low interest rate on loans, but some businesses are unaware of the benefits of being a member of savings and credit cooperatives, This is why not all have been able to progress in the same way due to various unforeseen expenses that may arise in the course of time, so many ventures decide to close and in turn generates unemployment of those who worked in those ventures, and this has produced a rise and fall in the development of ventures in the country during the period 2010-2019.

For this reason, the objective of this research work is to determine the level of development of the popular and solidarity economy in Ecuador during the aforementioned period, making a theoretical conceptualization of the Popular and Solidarity Economy, to determine how beneficial the savings and credit cooperatives have been by analyzing their development.

The popular and solidarity economy itself is a voluntary grouping of a group of people whose purpose is to strengthen their capital to meet their social and economic aspirations by working fairly for the benefit of all, creating a culture of good and peace.

Since 2011, through the Law of Popular and Solidarity Economy, the EPS is recognized as a form of economic order in which its members, either separately or in groups, coordinate and carry out events of production, exchange, marketing, financing and consumption of property and services through links according to solidarity, The 
purpose of the Organic Law of Popular and Solidarity Economy (LOEPS) is to distinguish, promote and strengthen the popular and solidarity economy and the popular and solidarity financial sector in its activity and linkage with other sectors of the economy and the State, In addition, it seeks to strengthen the practices of the EPS that are developed in the communes, communities, peoples and nationalities, and in their productive economic entities to achieve the Sumak Kawsay, for this reason, the LOEPS establishes a common legal framework for natural and legal persons that integrate the EPS and the financial, popular and solidarity sector, according to the aforementioned Law, it is intended to apply the regime of rights, responsibilities and benefits of the people and institutions applied to this mandate and, set the public institutionality that will carry out the steering, regulation, control, promotion and accompaniment.

Ancestral practices have also been of great importance for the country's economy, since over time they have been a fundamental basis for the development of popular and solidarity economy, it is true that the Andean culture is a key in this economic model, since in the construction of institutionality the practices of social and solidarity economy could be considered as a result of government action and not as they are in reality (Romero, 2016, p. 234).

According to the Organic Law of Popular and Solidarity Economy, the organizations of this sector are guided by the following principles:

The search for the good life and the common good: it is a matter of finding the common joy of the obligations of all its members.

The priority of labor over capital and of collective interests over individual interests: their preference is for labor and collective benefits, so that their agreement is with the community.

Fair trade and ethical and responsible consumption: This trade is focused on dialogue, transparency and respect that seeks greater equality in international trade.

Gender equity: Authorizes gender inclusion without discriminating against women's skills and abilities.

Respect for cultural identity: There is no isolation or discrimination for the different cultures of each of the participating members. Selfmanagement: There is democratic and participatory selfmanagement, self-control and self-responsibility. 
Social and environmental responsibility, solidarity and accountability: It maintains agreements with the community and the environment by providing them with services or solutions.

Equitable and solidary distribution of surpluses: The distribution of surpluses with its members is equitable without prevailing the individual use.

According to Gil et al.(2010) this economy is fundamental for those small businesses that in one way or another want to achieve success, associating with a group of people in order to get out of poverty together and benefit the community. According toOsvaldo(2014) it is tablece as principles are fundamental in any organization to make known to all members of a society in which it is based the work to be done, their aspirations, their interests and goals to be achieved in that organization. In research such as those of Castelao(2016); Molina et

83 al. (2010); Sanchez (2016) establish that the meaning that, through principles and characteristics, the organizations regulated under the popular and solidarity economy, is clearly differentiated from private entities, based on this, it can be said that the popular and solidarity sector, is concerned with ensuring the rights of the member in an equitable manner.

In the analysis made by Ceballos(2015) to Article 283 of the Constitution, the legal framework of the EPS existing in Ecuador allows the aforementioned sector to be made visible and therefore considered as a fundamental axis of the country's development. For Pliego(2014) describes that when the Organic Law of Popular and Solidarity Economy and its Regulations were published in 2012, the Superintendence of Popular and Solidarity Economy was created with the objective of contributing to the Good Living of its members and the community in general. Thus, the economic system is social and solidary, and is integrated by public, private, mixed, popular and solidary forms of organization.

\section{Materials and Methods}

This work carried out the information gathering through the methodology of bibliographic review, the database of the Catholic University of Cuenca was used to elaborate it, in addition several documents were selected, this method was used to evaluate the development that the popular and solidarity economy has had in the last decade, allowing the generation of new sources of work. Also, it 
was considered those authors who speak specifically of the development that this economic model has had in the last decade, for this reason this study aims to inform and guide, Ecuadorian citizens, about the benefits and advantages provided by the popular and solidarity economy, and how imparts this is for the economic development of Ecuador, in addition, various research articles and magazines have been found for the in-depth study of the Popular and Solidarity economy in Ecuador.

\section{Results}

Universities with historical heritage have had processes not exempt of problems and particularities in the conformation of their diverse expressions. On many occasions we witness the in situ assessment of restorations of imposing facades or monuments that are only small reflections of the University Cultural Heritage (hereinafter PCU), in which movable and immovable assets such as architecture, archaeological sites, works of art, manuscripts, books and other objects of artistic, historical or archaeological interest are mixed, as well as scientific collections of all kinds, assets of ethnological value, technical documentary or of any other cultural nature regardless of their origin or owner. (Diaz, 2012, p.125)

The PCU is not exhausted in the purely historical, artistic or material, also its intangible heritage has been the result of the creative activities of the university community, cultural traditions, sports, religious and today are preserved with the responsible use of the historical memory that houses the university in every corner. Within this intangible heritage, the documentary support constitutes a legacy for humanity, and its protection, dissemination and enrichment depends on everyone. (Dorado \& Hernández, 2015)

Universities as model centers of education through their libraries or information centers have the unavoidable mission of sensitizing and raising awareness among the university community and the rest of society about the protection of their cultural heritage. However, at present, the functions of university libraries need to be updated in accordance with the trends and needs that contemporary heritage demands, so that they can develop sensitive experiences, communication strategies and educational alliances that empower the communities and the surrounding population. 
In the midst of all these expressions of heritage, one aspect is vital today, we refer to the preservation of historical documentation in the university environment, mostly reduced to remain in their archival institutions, libraries and offices. This heritage is complex, and its degrees of conservation vary according to the management implemented by the higher education institutions, the knowledge of the personnel designated for these functions, the investment in technology or materials for these purposes and the will of preservation existing in the authorities.

Foster (1995) goes deeper into these issues by proposing the composition of the documentary heritage in those informative elements and documents that are carriers of transcendental data for the current development of the academic, pedagogical and research purposes of the university; as well as those that contemplate in their content some transcendental fact; describe a proven, authentic and reliable relationship that is part of those events that have had a direct impact on the development of the university, and have a relevant influence on the process of its social development (academic publications, prints, audiocassettes, videocassettes, tapes, CD's, DVD's, maps, cartographic references, etc.)

Although this conceptualization includes more contemporary expressions, a large part of these documentary treasures are related to collections that may date back centuries based on documents that include university council minutes, rector's resolutions, academic records, photographic collections, pamphlets or rare and valuable books. In many cases, it has been observed that some institutions have lost important collections due to mismanagement, infrastructure problems or dangers caused by humidity and neglect.

Along with these collections we cannot fail to mention that much of the documentation that is currently being generated constitutes in itself a new contribution to this documentary heritage, inevitably connecting universities with the future knowledge society that can be generated from academic, research or community outreach processes (Takayanagui, 2014).

With the development of science and technology and the application of new technologies, there has been an explosion of documents and a diversification of the media containing information. As León (2006) explains, there has not been a proportional increase in the amount of 
space available for storage, which makes it necessary to seek formulas that do not require a large physical expansion.

Universities in developing countries have not been exempt from the evolutionary process of information supports, nor from the consequences derived from the contemporary scientific, technological and documentary explosion, but their efforts to alleviate this phenomenon are slow and complex due to the serious economic difficulties suffered by some nations. As a result of these conditions, documents with supports in different materials coexist in university libraries and archives, due to the historical juxtaposition of the carriers, which has caused documents of scientific, historical or artistic value created in the past to require efficient restoration. This is an excessively time-consuming activity and requires a large amount of resources and highly qualified personnel. Given these circumstances, it is recommended to strive to create the ideal conditions for proper preventive conservation of documents, as well as to provide staff with the necessary knowledge for this arduous task and invest the few resources available in taking all appropriate measures to prevent the deterioration of the supports and the loss of the information they contain. (Palma, 2013)

In parallel, heritage conservation management cannot be divorced from social uses and the links imposed by science and technology today, which must stimulate a process that goes beyond the mere restoration of conserved goods. It is not only a problem of material and physical conservation but also of the involvement of those who preserve the memory and help to define the historical conscience of a society and the valuation of its own path.

This is connected with a trend that currently defends from the perspective of the librarian field the open access to the information heritage for its institutionalization within the legal frameworks of universities. This is based on an operational model that can be coordinated by university and specialized libraries that aims to sustain, manifest and regulate such access as a right of citizens and institutions, promote the use of the information heritage, encourage the autonomy of open access, disseminate the value and usefulness of open access to scientific and humanistic information for social benefits, among others (Palma, 2013).

Management of University Documentary Heritage: fundamental issues. 
Cultural management is powerfully influenced by the changing and diverse contemporary environment. Among the characteristics of the times that influence the performance of management are: mercantile, financial and cultural globalization, the accelerated development of communications, computerization and transportation, the sharpening of economic, technological and social inequalities, the concentration of economic power outside the state, the increase in ethnic conflicts and migration processes, the deterioration of the environment and the acceleration of processes of cultural homogenization and the destruction of identities.

These characteristics, which imply uncertainty in management processes, are present in the complex realities of underdeveloped countries and pose a challenge for the preservation of our common heritage. The cultural management of heritage responds to a global coverage, where the fields of cultural administration (planning, 87 coordination, direction and evaluation) and the dimensions of cultural activities (animation, creation, preservation, dissemination) are combined, ensuring an adequate and efficient development of policies both in macro social systems and in those related to the behavior of entities, programs or specific projects of the sector. (UNESCO, 2003)

The projections of heritage management cannot be disconnected from cultural policies, Garcia (1999) identifies the complexity of this process as a:

set of interventions carried out by the State, civil institutions and organized community groups in order to orient symbolic development, satisfy the cultural needs of the population, and obtain consensus for a type of order or social transformation. (p.18)

In this sense, cultural policies constitute the symbolic unity of a nation, the distinctions, divisions and links within it and with respect to other nations, and heritage management constitutes a broad process that involves different networks, actors and interactions. Thus the conceptualization of management and conservation of the PCU is expressed as a conscious process, which establishes purposes and commitments of the subjects involved to promote learning and attitudes. (González et. al, 2018)

The management of the PCU must take into account these external conditions without losing sight of certain deficiencies that must be overcome internally, mainly associated with the management and 
preservation of its assets, which can be summarized in the following aspects:

Lack of knowledge and non-observance of current legislation on the protection of cultural heritage by those responsible for its preservation. The legal systems include a wide range of legal provisions that implement the political interest of the State to protect its heritage, but their regulation and implementation has different nuances within the public and private sectors.

Incomprehension's in the design of an institutional policy with respect to the management, handling and preservation of university heritage aimed at guaranteeing its identification, protection and dissemination, not only within the university community but also outside of it.

Lack of knowledge of the totality of the heritage assets of the 88 universities, specifically those of a documentary nature such as reports, offices, memorandums, books, articles, journals, book chapters, papers, theses, among others: it is presumed that some of these are not identified, which implies a lack of knowledge of their characteristics, state of conservation and historical-heritage value and hinders the execution of concrete actions with respect to their safeguarding.

Problems with the state of conservation of cultural heritage: due to factors such as climate, age, dust and partial or total damage, deficient training of those responsible, among others. There are a large number of assets that are in a poor state of conservation, which is detrimental to their durability. In the specific case of heritage documentation, these require conservation conditions that are sometimes very costly such as air conditioning-, qualified personnel for handling and maintenance, the necessary equipment for image and/or sound reproduction, conservation units and adequate furniture for special materials, just to mention some of the shortcomings.

Within all these requirements, documentary heritage constitutes a fundamental nucleus. The documentary wealth contains material not only related to the universities that preserve them, but to the history of each country, it must be organized in such a functional way that it helps us to understand more about our past, this process of revaluation of effective strategies must take into account the uses of science and technology where an ethical and social responsibility of the scientists responsible for them prevails. (Morte \& Esteban, 2019) 
The relationship Science-Technology-Conservation of University Documentary Heritage.

PCU management must evolve in correspondence with the archival reality worldwide. This situation leads us to the application of the socalled hybrid systems, which means producing, storing and maintaining documents on paper and other media that technology offers us, such as microfilm or electronic media, so that at this point of convergence to ensure the preservation of archival documents for as long as they are needed. Hybrid systems are used as a way of guaranteeing the preservation of information, so as not to have problems in the attention of citizens and the legal order in general that public documents support (León, 2006).

The universities are destined to adopt a system for the management of their documentary heritage in which the preservation and integrity of

89 all electronic records and traditional archival documents are complemented in an efficient way and with the transparency of their free access.

Management, seen in a multifunctional sense, should connect the university documentary heritage with knowledge, rather it should be treated, for the sake of accuracy, as a management of internal and external organizational information for the generation of new collections that will influence the development of products and services with high added value, because knowledge can only be managed converted into information, gathered, processed, organized, stored and disseminated through databases, shared information networks, virtual communities, among other contemporary means of data and information transfer.

In the new university educational models, information, documentation and knowledge management is emerging as a strategic component of the first magnitude. The traditional orientation of the tactical nature of information or documentation management projects changes when it is considered a true component of the educational strategy. The sustained growth in the training of professionals in these areas of knowledge has been of great importance in this regard, although unfortunately there are great differences between countries.

We must not lose sight of the necessary links that must exist between documentary heritage and the social function of knowledge, as Bernal (1939) announced: 
To ensure the knowledge base that will allow the construction on rational bases of a national project based on the traditions, values, interests and expectations of the people.

To extend and turn into a collective patrimony the capacity of thought that allows us to confront dogmatism, mysticism, irrationality, the uncritical acceptance of interpretations and projects that are not supported by practical experience and lack scientific and cultural foundations that are duly argued.

Strengthen national self-awareness through the in-depth study of national history and culture, where the care of the documentary base itself, contained in archives and databases, is fundamental.

Ability to develop, based on knowledge, public deliberation of the issues that most interest the nation and its citizens. The discussion and 90 evaluation of public policies, the exercise of social criticism, are constituent elements of a truly participatory democracy that encourages the exercise of a committed citizenship.

Education in general and the technical preparation of workers allow for a reasonable technological learning capacity that makes possible the functioning and development of the productive sector. Productivity has cultural roots and labor performance is not indifferent to educational and technical capacity. Any strategy implemented in universities for the protection of their documentary heritage lacks the basic support if they do not have the right people to deal with the technologies and their scientific backing.

Maintain a receptive and at the same time critical and selective attitude towards the cultural, scientific and technological production that circulates in the global world today. In a world where a truly overwhelming volume of information circulates, there is a great deal of knowledge available. A good part of the problems that affect society require technical resources that it will not be necessary to create. It may seem a simple task, but the mere ability to search, find, select and adapt is actually a complex and highly creative task.

The strategies for the fulfillment of this series of objectives in the documentary heritage management process must be based on the profound technological revolution we are living through, and as part of it, the introduction and appropriate use of both computers and various computer products. The new information technologies have definitely brought about a profound change in the working methods of 
any type of professional and in any work carried out in the so-called information society. It is a fact, unanimously accepted, that a social and cultural transformation has taken place that is giving rise to a new industrial environment and new cultural forms of relationship and personal and group intercommunication.

The aforementioned transformation continues to affect all professional fields and their fields of application: commerce, finance, services, entertainment, training, social media, editing-publishing... and, obviously, the field of archives, libraries and university information and documentation centers and services.

Consequently, communicators, information professionals in general and documentalists have a new role to play in the era of electronic information, characterized by digitization, integration and globalization, as an immense universal data network or World Wide 91 Web. The network of networks, the Internet (and its derivations, Intranet/Extranet), is therefore presented as a new means of communication, as the current instrument par excellence for the reception, consultation, production and dissemination of information of all kinds. (Serrano, 2020)

We are in a digital era, at a time when the available technologies of image and sound digitization, robotics and management of large databases and networks allow any professional in different fields of work to consult all kinds of information, produce their own content, digitize their material and integrate it into a complex system of remote access and dissemination. (Leija et. al, 2020)

Nowadays, with the development of science and technology and the application of new information and communication technologies (NICT), there has been an explosion of documents and a diversification of the media that contain information.

As Bustelo(2019) refers:

In this context, when organizations begin the process of digital transformation that inevitably implies that paper documents cease to exist, we are forced to make explicit new conventions that allow us to understand and define what an "electronic document" is and, with this change, new spaces are opened to establish new good practices to manage them. (p. 4) 
In addition, various duplication techniques have been developed, such as facsimile reproduction, photocopying, microfilming, photography and digitization, among others, which facilitate the preservation of original documents by limiting access by users. With gradual work based on these experiences, a preservationist culture can be generated among users. (Cascón-Katchadourian et. al, 2018).

NICTs should constitute a fundamental support for the management of the PCU; they have improved the search, storage, retrieval and dissemination of information, streamlining and improving access and service to users. However, there has not been a proportional increase in storage space, which makes it necessary to seek formulas that do not require a large physical expansion.

Digital technology promises to be one of the possible solutions to this problem because of the advantages it offers, but the process of 92 digitization of collections is a complex and costly process that requires strategic decisions by the institutional management. Although digitization offers the possibility of storing, managing and disseminating a large volume of information, rapid retrieval of accurate information and online access, it is a relatively new technology and some aspects remain to be resolved, which are still controversial and, rather than disadvantages, constitute challenges that will have to be solved in the near future (León, 2006).

Among these challenges are the high initial investment, the longevity of the media used is short compared to that of quality paper, the technology used for storage and retrieval of information becomes obsolete relatively quickly and backward compatibility is often limited, the necessary refreshment or migration of stored data to a new medium and the renewal of technology in relatively short periods, the need for renewal of the technologies used the digitization project is expensive and the invulnerability to certain deterioration factors is not fully demonstrated. The existence of fungus species that affect compact discs is known.

Many other advantages and disadvantages could be mentioned in the use of this technology, but the main thing is that it is a tool, not an end in itself, and the success of digitization programs lies in knowing how to use it to achieve the proposed objectives.

Attention should also be paid to the importance of using technology not only for the digitization of documentary and bibliographic collections, but also for the creation of databases, the use of the 
Internet and repositories for the dissemination of the university's documentary heritage, all this in close connection with the training and specialization of specialized personnel. It is essential to take into account the strategies of communication, dissemination and training of the public and the students that interact in the university with the use of blogs, web pages, brochures and the intervention in radio and TV to promote values in different social sectors. Likewise, a necessary bridge is built with the outside world in the search for agreements and resources to acquire technology to facilitate preventive conservation, cataloging and dissemination of documentary heritage and everything that derives from it in terms of research. (Macías \& Bujardón, 2010; Quirós \& Polo, 2018).

For this type of situation, awareness-raising (understanding by awareness-raising the work of dissemination and extension of scientific knowledge by the university community that carries out 93 research in the territory comprising the heritage to the local community, with the advice of personnel qualified in such tasks) is considered as a way of counteracting the negative effect of the exercise of ignorance about the potential for scientific and economic development of the heritage. In this sense, complementary actions are needed, for example: the aforementioned work of dissemination and extension of the acquired knowledge.

The processes of heritage interpretation and management are currently a new discipline in the development of heritage enterprises, in order to resolve a major dilemma: to enhance the value of heritage and its conservation, while at the same time allowing a deep understanding of its various expressions with benefits for the communities that carry it.

Within the framework of the implementation of a responsible management of documentary heritage, it is necessary to involve various social actors and institutions to promote scientific research based on the management and dissemination of knowledge as a significant resource. In this process that arises from the use of university documentary heritage, academic exchanges with scientists and specialists from other universities can be stimulated to break any kind of cultural obstacle in function of a responsible and modern management of documentary heritage linked to technology and science. (Garcia et. al, 2018). 
In the spirit of cultivating social responsibility to protect and disseminate the university documentary heritage, another series of actions can be taken into account, such as arranged and guided visits to show the different collections within the archives or libraries, determining in advance the type of people to be visited, their academic level, age and purpose, among others. Each group will be made aware of the importance of the university's documentary heritage for them and for society in general and how they can use it for educational, personal or research purposes.

Another type of activity is that of pedagogical services that consist of the interaction that should exist between the university and educational centers (schools, universities), promoting the educational dimension that archives and libraries can fulfill, based on the use of their collections for didactic purposes. In this way, it will be possible to stimulate reflection and critical thinking among students by

94 bringing them closer to their immediate reality through documents in workshops or information literacy courses.

\section{Conclusions}

After conducting a literature review analysis, it was observed that the popular and solidarity economy itself is a voluntary grouping of a group of people whose purpose is to strengthen their capital to meet their social and economic aspirations by working fairly for the benefit of all, creating a culture of good and peace. In addition, it contributes to the social and economic development of natural persons, but, prioritizing the Pymes at the moment of attributing credits and that its main priority, is the well-being of its partners, for which they are a fundamental part for the taking of important decisions. They have also had a successful economic development in the last decade, since they have increased both their economic capital and their members, and currently there are 887 cooperatives.

\section{References}

Agotegaray, M. A. (2008). Social capital in organizations : its generation from training [online]. $\mathrm{PhD}$ thesis in Administration, Universidad Católica Argentina, Facultad de Ciencias Sociales y Económicas.

http://bibliotecadigital.uca.edu.ar/repositorio/tesis/capitalsocial-organizaciones-generacion- capacitacion.pdf. 
Castelao, M. E. (2016). Public policies and their vision of the social and solidarity economy in Argentina. Revista Mexicana de Ciencias Politicas y Sociales, 61(227), 349-378. https://doi.org/10.1016/So185-1918(16)30032-0.

Ceballos, A. S. D. (2015). Eurozone crisis: structural failures and austerity policies. Economia UNAM, 12(35), 45-68. https://doi.org/10.1016/j.eunam.2015.09.003.

Gil, R. B., Vallejo, J. M., \& Pérez, J. M. P. (2010). Image associations as determinants of satisfaction in the Spanish banking sector. Cuadernos de Economia y Direccion de La Empresa, 13(43), 8-35. https://doi.org/10.1016/s1138-5758(10)70008-6

Molina, M. E. R., Saura, I. G., \& García, H. C. (2010). The moderating effect of age on the relationship between perceived value, retailer ICT and customer loyalty. Cuadernos de Economia y Direccion de La Empresa, 13(43), 64-91. https://doi.org/10.1016/s1138-5758(10)70010-4.

Orellana-orellana, C. P., Orellana-orellana, E. F., \& Olivo-olivo, M. A. (2020). Management Model for Administrative Processes in Popular and Solidarity Economy enterprises *. 4, 343-351.

Osvaldo, M. (2014). Ecuador: overview and recent economic developments. Economía Informa, 385, 100-108. https://doi.org/10.1016/s0185-0849(14)70424-4.

Pliego, M. (2014). Conjunctural analysis of fiscal policy in Mexico 1993-2004*. Economía UNAM, 11(32), 59-76. https://doi.org/10.1016/s1665-952x(14)70452-9.

Romero, X. V. E. (2016). The construction of a progressive tax policy in Mexico. Economia Informa, 398, 75-88. https://doi.org/10.1016/j.ecin.2016.04.006.

Sánchez, C. M. (2016). El reto de incorporar a México al ttp en el capitalismo del conocimiento superando su integración al tlcan. Economía Informa, 40o, 40-66. https://doi.org/10.1016/j.ecin.2016.09.004 